\title{
The nucleus of the solitary tract and the coordination of respiratory and sympathetic activities
}

\section{Daniel B. Zoccal*, Werner I. Furuya, Mirian Bassi, Débora S. A. Colombari and Eduardo Colombari}

Department of Physiology and Pathology, School of Dentistry of Araraquara, São Paulo State University (UNESP), Araraquara, Brazil

\section{Edited by:}

Thiago S. Moreira, University of Sao

Paulo, Brazil

\section{Reviewed by:}

Cara Hildreth, Macquarie University, Australia

Thiago S. Moreira, University of Sao Paulo, Brazil

Robert W. Putnam, Wright State

University Boonshoft School of

Medicine, USA

*Correspondence:

Daniel B. Zoccal, Department of Physiology and Pathology, School of Dentistry of Araraquara, São Paulo State University, Rua Humaitá, 1680 CEP: 14801-903, Araraquara, Brazil e-mail: zoccal@foar.unesp.br
It is well known that breathing introduces rhythmical oscillations in the heart rate and arterial pressure levels. Sympathetic oscillations coupled to the respiratory activity have been suggested as an important homeostatic mechanism optimizing tissue perfusion and blood gas uptake/delivery. This respiratory-sympathetic coupling is strengthened in conditions of blood gas challenges (hypoxia and hypercapnia) as a result of the synchronized activation of brainstem respiratory and sympathetic neurons, culminating with the emergence of entrained cardiovascular and respiratory reflex responses. Studies have proposed that the ventrolateral region of the medulla oblongata is a major site of synaptic interaction between respiratory and sympathetic neurons. However, other brainstem regions also play a relevant role in the patterning of respiratory and sympathetic motor outputs. Recent findings suggest that the neurons of the nucleus of the solitary tract (NTS), in the dorsal medulla, are essential for the processing and coordination of respiratory and sympathetic responses to hypoxia. The NTS is the first synaptic station of the cardiorespiratory afferent inputs, including peripheral chemoreceptors, baroreceptors and pulmonary stretch receptors. The synaptic profile of the NTS neurons receiving the excitatory drive from afferent inputs is complex and involves distinct neurotransmitters, including glutamate, ATP and acetylcholine. In the present review we discuss the role of the NTS circuitry in coordinating sympathetic and respiratory reflex responses. We also analyze the neuroplasticity of NTS neurons and their contribution for the development of cardiorespiratory dysfunctions, as observed in neurogenic hypertension, obstructive sleep apnea and metabolic disorders.

Keywords: NTS, neurotransmission, sympathetic activity, respiration, chemoreflex, cardiorespiratory coupling

\section{INTRODUCTION}

A dualistic concept of cardiovascular and respiratory systems still prevails. However, the fundamental organizational precept of cardiorespiratory control may be viewed as a unitary system. Accumulating evidence strongly supports the notion that these systems imperatively operate in a coordinated way to match the processes of pulmonary ventilation and tissue perfusion (Hayano et al., 1996; Giardino et al., 2003; Ben-Tal et al., 2012). Recordings of parasympathetic and sympathetic nerves supplying the heart and blood vessels indicate that the autonomic activity controlling cardiac output and vascular resistance displays robust patterns of discharge entrained with the respiratory cycle (Adrian et al., 1932; Malpas, 1998; Barman and Gebber, 2000; Bouairi et al., 2004; Gilbey, 2007; Grossman and Taylor, 2007). As a consequence, the respiratory-related modulation of cardiovascular parasympathetic and sympathetic activities produces rhythmical oscillations in baseline heart rate (respiratory sinus arrhythmia) and arterial pressure levels (Traube-Hering waves) (Moraes et al., 2012b). The pattern of respiratory modulation of autonomic activity modifies according to the metabolic demand (blood gas changes, for instance) and contributes to generate appropriate respiratory and cardiovascular reflex responses (Dick et al., 2004; Molkov et al., 2011). Therefore, it is undeniable that the respiratory and cardiovascular systems establish interactions to form a unique and dynamic system. In this review, we discuss the potential neuronal sources underpinning the coupling of cardiovascular and respiratory activities, with special attention to the neurons of the nucleus of the solitary tract (NTS), which, due to their anatomical, neurochemical and electrophysiological properties, allow the processing of characteristic, often coupled, patterns of respiratory and autonomic responses to specific physiological and pathological mechanisms.

\section{RESPIRATORY-SYMPATHETIC COUPLING: VENTROMEDULLARY NEURONS AND BEYOND}

Over the last decades, efforts have been made to identify the cellular sources and neurochemical mechanisms responsible for the cardiorespiratory coupling. Several studies have focused on the interaction between respiratory and sympathetic activities due to its relevance in the control of arterial pressure and its contribution to the development of arterial hypertension (Zoccal et al., 2008; Simms et al., 2009; Toney et al., 2010). Although the pattern of respiratory-sympathetic coupling may vary according to the animal species, experimental condition (for instance, the presence of anesthesia) and the nerve recorded (Malpas, 1998), baseline sympathetic nerve activity to blood vessels in mammals exhibits 
phasic bursts that emerge during inspiratory/post-inspiratory phase (Zhou and Gilbey, 1992; Dick et al., 2004; Zoccal et al., 2008). Part of the respiratory oscillations of sympathetic activity is associated with cyclic stimulation of peripheral afferent receptors, including arterial baroreceptors and pulmonary stretch receptors (Bernardi et al., 2001). However, the respiratory rhythmicity of sympathetic activity persists after vagotomy and decerebration (Barman and Gebber, 1980), indicating that the coupling of respiratory and sympathetic activities is generated within the brainstem due to connections between neurons of sympathetic and respiratory systems.

The ventral surface of the medulla oblongata has been pointed out as the main site of synaptic interactions between respiratory and sympathetic neurons. The ventral medulla houses the pre-sympathetic neurons of the rostral ventrolateral medulla (RVLM) - the major source of excitatory inputs to the preganglionic sympathetic neurons of the spinal cord that maintain baseline arterial pressure in adequate levels (Guertzenstein and Silver, 1974; Ross et al., 1984). Intermingled with the RVLM neurons are the respiratory neurons of the ventral respiratory column (VRC), which are considered the kernel of respiratory rhythm and pattern generator (Smith et al., 1991, 2007; Moraes et al., 2011). The VRC is composed by four distinct sub-nuclei: Bötzinger complex (BötC), pre-Bötzinger complex (pre-BötC), rostral ventral respiratory group (rVRG) and caudal ventral respiratory group (cVRG) (Bianchi et al., 1995). Due to their anatomical proximity, it has been suggested that the respiratory neurons of the ventral medulla establish synaptic connections with the pre-sympathetic neurons of the RVLM and generate the respiratory oscillation in the sympathetic activity (McAllen, 1987; Haselton and Guyenet, 1989; Zhou and Gilbey, 1992; Miyawaki et al., 1995; Zoccal et al., 2008).

Recent studies performing intracellular recordings of the RVLM pre-sympathetic neurons using the in situ preparation of rats identified different populations of $\mathrm{C} 1$ and non-C1 neurons that exhibit spontaneous excitatory or inhibitory post-synaptic potentials phase-locked with the respiratory cycle (Moraes et al., 2013), thus supporting the notion that the RVLM is an important site of respiratory input convergence (Haselton and Guyenet, 1989; Miyawaki et al., 1995). In addition to the RVLM, the GABAergic neurons of the caudal ventrolateral medulla (CVLM), which establish synaptic inputs with the RVLM neurons and provide the tonic inhibitory baroreflex control of sympathetic activity (Schreihofer and Guyenet, 2003), also display distinct firing patterns coupled to the respiratory cycle (Mandel and Schreihofer, 2006). Therefore, there is convincing evidence that the presympathetic neurons of the RVLM, either directly or indirectly through the CVLM, receive the respiratory inputs necessary for the generation of respiratory modulation of sympathetic activity. On the other hand, there are limited data on the literature suggesting the sources of respiratory inputs to the sympathetic neurons of the ventral medulla. Based on the fact the RVLM and CVLM neurons exhibit distinct respiratory-related patterns of discharge (inspiratory peak, post-inspiratory peak and inspiratory depression) (Haselton and Guyenet, 1989; Mandel and Schreihofer, 2006; Moraes et al., 2013), it is possible to speculate that both inspiratory and expiratory neurons of the VRC may establish excitatory and inhibitory synapses with the sympathetic neurons. In agreement with this idea, anatomical studies have evidenced axon varicosities from the BötC neurons closely apposed to the RVLM neurons, strongly suggesting synaptic contacts between these two neuronal populations (Sun et al., 1997). Studies showing that ponto-medullary transection eliminated baseline respiratory-sympathetic coupling also suggest that the respiratory neurons of the pons, which send projections to ventromedullary regions (Dobbins and Feldman, 1994; Kubo et al., 1998), may contribute to baseline respiratory-sympathetic coupling (Baekey et al., 2008).

In addition to the lack of clear anatomical and functional data showing the neural substrates responsible for the generation of respiratory modulation of sympathetic outflow at resting conditions (eupnea), changes in the respiratory pattern modify the pattern of respiratory-sympathetic coupling. For instance, peripheral chemoreceptor activation by cytotoxic (with cyanide) or hypoxic hypoxia reflexly induces marked increases in inspiratory and expiratory motor activities combined with a sympathoexcitatory response (Braga et al., 2007; Moraes et al., 2012a). This increase in sympathetic activity is characterized by the emergence of high amplitude bursts during the post-inspiratory phase (Dick et al., 2004; Mandel and Schreihofer, 2009; Costa-Silva et al., 2010) — a discharge pattern different from that observed at baseline conditions (Figure 1). Changes in the respiratory pattern and in the respiratory-sympathetic coupling are also observed in conditions of hypercapnia, which causes an increase in the sympathetic activity during the late part of expiratory period (prior to the phrenic burst) coupled with the generation of active expiratory pattern (Boczek-Funcke et al., 1992; Molkov et al., 2011). Therefore, multiple synaptic interactions may exist between respiratory and sympathetic neurons, and either the recruitment or the strengthening of these interactions essentially depends on the activation of neurons regulating the respiratory pattern.

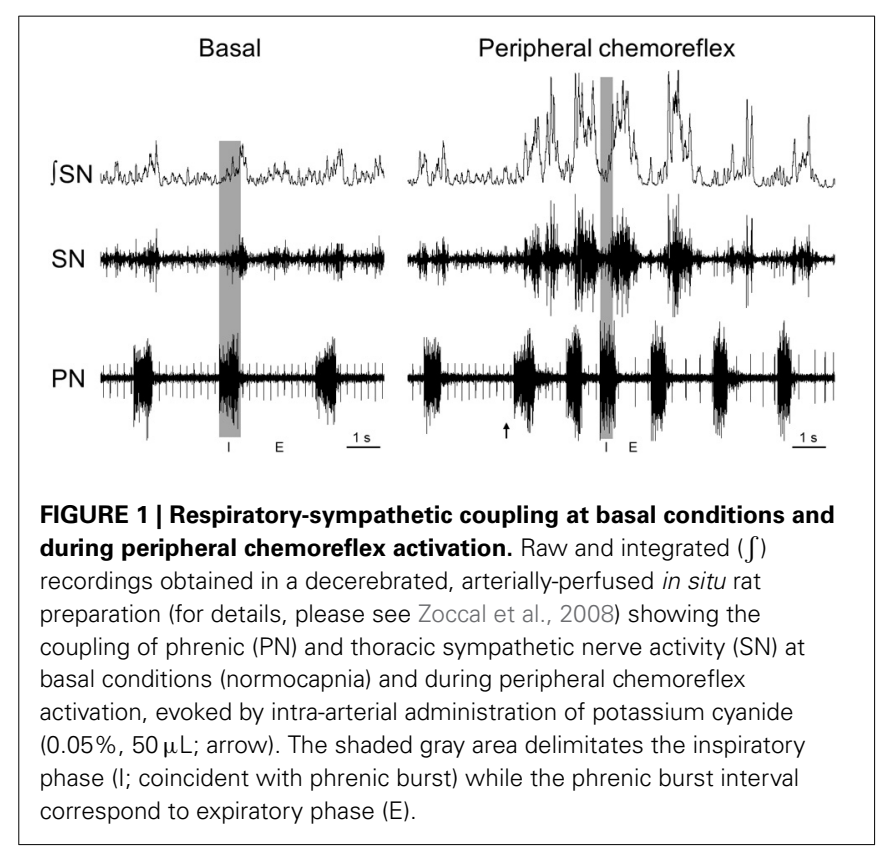


Accordingly, in spite of the unquestionable role of the ventromedullary neurons on the control and integration of respiratory and sympathetic activities, other brain areas must be considered as critical pieces of the circuitry regulating the coupling of respiratory and sympathetic activities. In this scenario, the neurons of the nucleus of the solitary tract (NTS) may play a relevant role for the coordination of the respiratory and sympathetic activities, especially in conditions of metabolic challenges, probably by acting as an integrative center to promote the activation of specific pathways due to the combination of neurochemical and neuroanatomical features.

\section{THE NTS CIRCUITRY AND ITS INTEGRATIVE ROLE}

The NTS is formed by heterogeneous groups of neurons located in the dorsolateral medulla, extending from the level of caudal portion of the facial nucleus to the caudal portion of the pyramidal decussation (Loewy, 1990; Dampney, 1994). Previous studies have demonstrated that the NTS plays a key role in the processing of visceral afferent information and transmission to other nuclei in the brainstem, forebrain and spinal cord (for review, see Andresen and Kunze, 1994; Sapru, 1996; Johnson and Thunhorst, 1997; Grill and Hayes, 2009). With respect to the cardiovascular and respiratory systems, the majority of the cardiorespiratory afferents converges preferentially to two different regions of the NTS: the intermediate NTS (iNTS), at the level of the area postrema, and the caudal NTS (cNTS), located caudal to the calamus scriptorius (Kumada et al., 1990; Loewy, 1990; Van Giersbergen et al., 1992). There is evidence supporting the notion that the iNTS and cNTS 2nd-order neurons are organized in clusters according to the afferent sensory information that they received. For instance, the neurons of the iNTS receive mainly afferent information from the arterial baroreceptors and from the slow-adapting pulmonary stretch receptors (SARs) whilst afferent inputs from peripheral chemoreceptors and rapid-adapting pulmonary stretch receptors (RARs) converge to the neurons of the cNTS (Mifflin et al., 1988; Mifflin, 1992; Machado, 2001; Kubin et al., 2006). Therefore, depending on the sensory information, distinct groups of NTS 2nd-order neurons are activated in order to recruit specific efferent pathways (Aicher et al., 1996; Bailey et al., 2006; Alheid et al., 2011; Song et al., 2011).

In association with the afferent-oriented organization, several bioactive molecules were identified in the NTS region, including amino acids (L-glutamate, GABA, glycine), biogenic amines (noradrenaline, serotonin, acetylcholine), purines (ATP and ADP) and peptides (angiotensin II, vasopressin, oxytocin), with relevant role in the neurotransmission and neuromodulation (for review, see Andresen and Kunze, 1994). These substances may act either post-synaptically or exert their function on presynaptic terminals modulating the release of other transmitters (Andresen and Yang, 1990; Shigetomi and Kato, 2004; Peters et al., 2008). Moreover, distinct 2nd-order neurons of the NTS exhibit different electrophysiological properties (De Castro et al., 1994; Doyle et al., 2004; Accorsi-Mendonca et al., 2011) that may contribute to differential timing control of the viscera-sensory information.

The combination of anatomical, neurochemical and electrophysiological features of the NTS neurons allow that this nucleus selectively integrates the sensory information and recruits specific neural pathways to generate appropriate cardiorespiratory responses. Given this significance, it is evident that changes in the normal functioning of the NTS neurons have great impact on the control of sympathetic and respiratory activities with pathological relevance, such as observed in animal models of arterial hypertension (Sato et al., 2002; Zhang and Mifflin, 2010) and in animals exposed to chronic intermittent hypoxia (Reeves et al., 2003; Kline et al., 2007; Almado et al., 2012). In the following sections, we discuss the potential role of the NTS in coordinating sympathetic and respiratory reflex responses, focusing on the neurotransmission and on the efferent brainstem pathways. The involvement of neural pathways from the NTS to mid- and forebrain regions will not be discussed in this review, since their involvement in the respiratory-sympathetic coupling is not clear.

\section{THE NTS AND THE RESPIRATORY-SYMPATHETIC COUPLING DURING PERIPHERAL CHEMOREFLEX ACTIVATION}

It is well known that prolonged exposure to low partial pressure of arterial oxygen $\left(\mathrm{PaO}_{2}\right)$ may produce persistent changes in the cellular activity leading to tissue dysfunction and death (Peña and Ramirez, 2005). To prevent this, a reflex system, named the peripheral chemoreflex, was developed in order to evoke appropriated and coordinated cardiovascular and respiratory responses to counteract the fall in $\mathrm{PaO}_{2}$. During hypoxia, the reduction of $\mathrm{PaO}_{2}$ is detected by chemosensitive cells, mainly located in the carotid bodies (Lahiri et al., 2006), which, in turn, send excitatory inputs to the 2nd-order neurons of the cNTS (Teppema et al., 1997; Cruz et al., 2010). These cNTS neurons are responsible for the integration and transmission of the peripheral chemoreceptor signals to other brain regions, leading to the emergence of sympathetic, parasympathetic and respiratory reflex responses that increase arterial pressure, reduce heart rate and enhance ventilation, respectively (Haibara et al., 1995; Colombari et al., 1996; Sapru, 1996). Previous studies suggested that the sympathoexcitatory response of the peripheral chemoreflex is dependent on the activation of NTS neurons that send excitatory inputs to the pre-sympathetic neurons of the RVLM (Aicher et al., 1996; Koshiya and Guyenet, 1996a). Studies performed in anesthetized rats (Dick et al., 2004; Mandel and Schreihofer, 2006) and unanesthetized in situ rat preparations (Costa-Silva et al., 2010) verified that the peripheral chemoreflex-induced sympathetic response is characterized by the emergence of higher amplitude bursts during post-inspiratory phase followed by inhibition during early inspiration (Figure 1). This pattern of sympathetic reflex response occurs entrained with the responses of augmented phrenic burst frequency (increased inspiratory drive) and increased abdominal burst amplitude (active expiration) (Moraes et al., 2012a). Therefore, it has been suggested that the sympathetic response to peripheral chemoreflex activation exhibit two components: one independent and another dependent on the activation of respiratory neurons (Koshiya and Guyenet, 1996b; Costa-Silva et al., 2010). Recent evidence suggests that the processing and coupling of the sympathetic and respiratory responses of peripheral chemoreflex rely on the recruitment of different neuronal population and/or neurochemical mechanisms in the cNTS (Braga et al., 2007; Furuya et al., 2014). 
Previous studies performed in anesthetized animals proposed that L-glutamate is a major excitatory neurotransmitter released by the peripheral chemoreceptor afferents in the cNTS (Zhang and Mifflin, 1993; Sapru, 1996; Gozal et al., 1999). However, studies performed in unanesthetized rats and in the in situ rat preparation failed to block the sympatho-excitatory and respiratory responses elicited by peripheral chemoreceptor activation after the antagonism of both ionotropic and metabotropic glutamatergic receptors (Machado and Bonagamba, 2005; Braga and Machado, 2006), indicating that neurontransmitters other than L-glutamate mediate the processing of these responses in the cNTS. Afterwards, it was verified that the antagonism of both ionotropic glutamate and P2-purinergic receptors in the cNTS reduced significantly the magnitude of sympathetic response to peripheral chemoreflex activation without affecting the tachypneic response (Braga et al., 2007; Braccialli et al., 2008). Therefore, the processing of sympathetic chemoreflex response by the cNTS neurons involves a complex interaction between L-glutamate and ATP (Accorsi-Mendonca et al., 2009). On the other hand, these neurotransmitters, at the cNTS level, apparently are not essential for the tachypneic reflex response, suggesting the involvement of an additional neurotransmitter system.

Since a functional cholinergic system has been described in the NTS (Ruggiero et al., 1990; Shihara et al., 1999), our group recently assessed the contribution of acetylcholine (ACh) in the processing of peripheral chemoreflex inputs in the cNTS using the arterially-perfused in situ rat preparation. We verified that microinjections of ACh in the cNTS did not change mean levels of sympathetic activity but increased phrenic burst frequency (Furuya et al., 2014). In spite of the lack of effects on mean levels of sympathetic activity, microinjections of ACh in the cNTS altered its coupling pattern with the respiratory activity, producing a shift of respiratory-related peak from the inspiratory to the post-inspiratory phase associated with an inhibition during the inspiratory phase (Furuya et al., 2014) - a pattern similar to that evoked by peripheral chemoreflex activation (Dick et al., 2004; Costa-Silva et al., 2010). Moreover, the antagonism of nicotinic receptors in the cNTS prevented the ACh-induced tachypnea and significantly reduced the tachypneic response following chemoreflex activation, without affecting the magnitude of sympathoexcitatory response (Furuya et al., 2014). In addition, the nicotinic antagonism in the cNTS also prevented the ACh-induced change in sympatho-respiratory coupling (Furuya et al., 2014). These data suggest that cholinergic mechanisms of the cNTS, at least in part, contribute to the processing of inspiratory response of the peripheral chemoreflex activation and its entrainment with the sympathetic activity. Recent studies have reported efferent projections from the cNTS to respiratory nuclei of the ventrolateral medulla and dorsolateral pons (Takakura et al., 2006; Alheid et al., 2011; Song et al., 2011) that may be involved with the emergence of respiratory responses of peripheral chemoreflex. However, further studies are still required to elucidate the respiratory nuclei targeted by the cNTS neurons activated by ACh.

Accordingly, the cNTS possesses an intrinsic neuronal circuitry that is essential for the precise coordination of evoked sympathetic and respiratory responses during hypoxia (Figure 2). Our recent data (Furuya et al., 2014) combined with previous studies

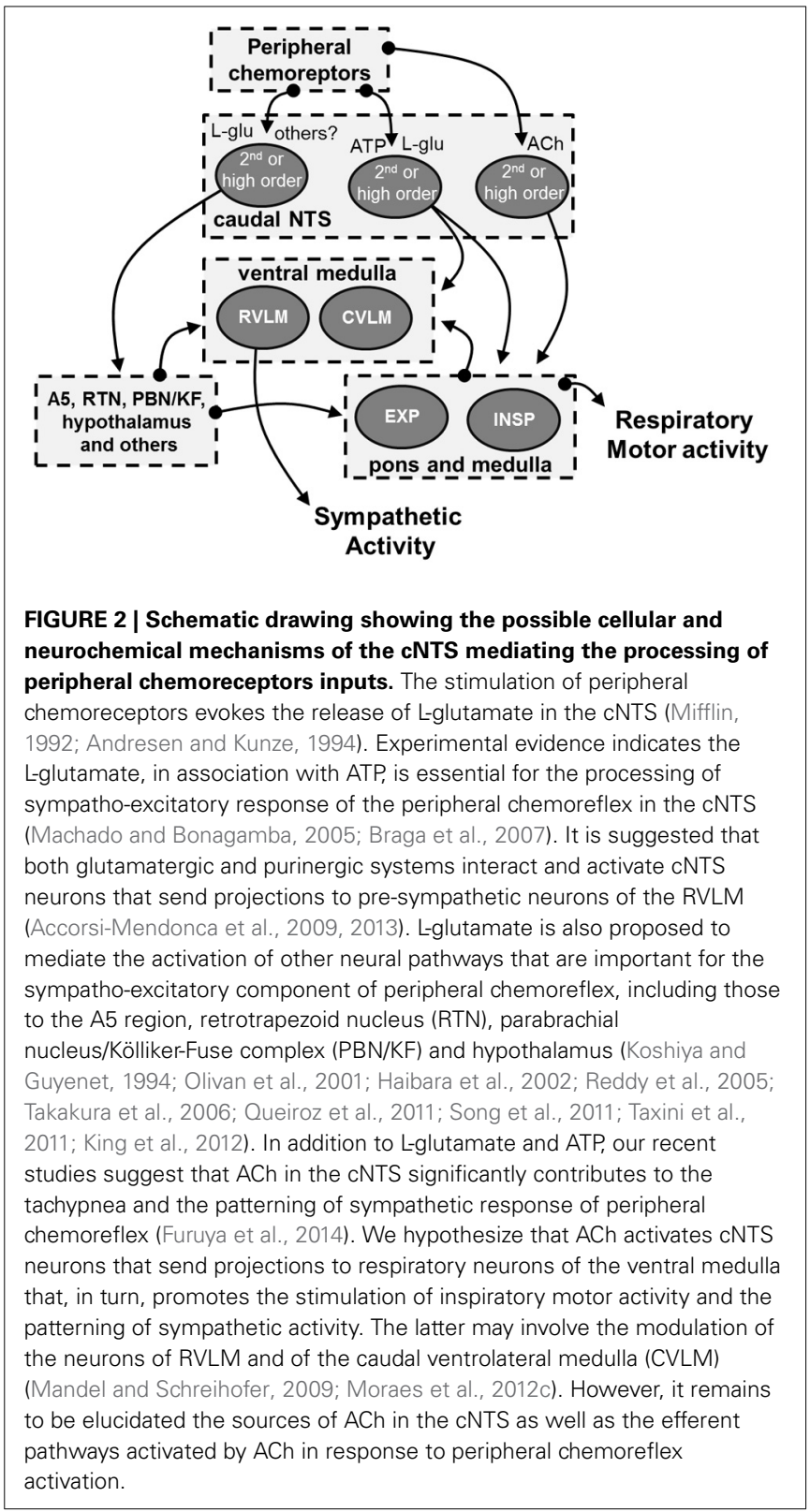

(Braga et al., 2007), suggest that the respiratory and sympathetic components of peripheral chemoreflex, in unanesthetized conditions, are processed by 2 nd-order cNTS neurons activated by different neurotransmitters, including L-glutamate, ATP and ACh. Whether ATP and ACh are released by afferent terminals, likewise L-glutamate, or by other cells of the cNTS (glia or neurons, respectively ATP and ACh) (Accorsi-Mendonca et al., 2013) still remain to be elucidated. Nevertheless, the selective activation of the 2nd-order neurons may be essential for the recruitment of specific neural pathways promoting the increase in sympathetic activity mainly during the post-inspiratory phase entrained with the increases in inspiratory and expiratory motor activities. The physiological meaning of the respiratory-sympathetic coupling observed during peripheral chemoreflex activation is not clear and requires further studies to be fully elucidated. Nonetheless, 
the sympathetic pattern during hypoxia is different from that observed at baseline conditions or during hypercapnia (Molkov et al., 2011), suggesting, therefore, that it may play a relevant role in matching oxygen uptake/delivery and tissue perfusion in conditions of low $\mathrm{PaO}_{2}$.

\section{THE NTS AND THE PROCESSING OF CARDIOVASCULAR AND PULMONARY FEEDBACK INFORMATION}

The iNTS neurons receive mainly the afferent information from mechanoreceptors located in the arterial blood vessels and pulmonary walls (Mifflin and Felder, 1990; Kubin et al., 2006). The arterial mechanoreceptors, named as arterial baroreceptors, are located in the aortic arc and carotid artery bifurcation and provide a powerful inhibitory feedback control of sympathetic activity, lowering the sympathetic vascular tonus in conditions of increased arterial pressure (Chan and Sawchenko, 1998; Gordon and Sved, 2002). This sympatho-inhibitory response is mediated by the activation of excitatory 2 nd-order neurons of the NTS that, in turn, promotes the inhibition of RVLM pre-sympathetic neurons through the activation of GABAergic neurons of the CVLM (Aicher et al., 1995; Schreihofer and Guyenet, 2003). Several pharmacological and electrophysiological studies suggest that the L-glutamate is the main neurotransmitter released by baroreceptor afferents (Reis et al., 1981; Bailey et al., 2006). However, Machado et al. (2000), reported that the antagonism of ionotropic glutamatergic receptors in the iNTS of awake rats was unable to block totally the hypotensive response to baroreflex activation (induced by electrical stimulation of the aortic depressor nerve), suggesting that the processing of baroreflex afferent information may either involve other regions of the NTS or other neurotransmitter systems than L-glutamate.

In association with the sympatho-inhibitory response, activation of baroreceptors also prolongs expiratory time, reducing the respiratory frequency (Richter and Seller, 1975; Lindsey et al., 1998; Baekey et al., 2010). According to Baekey et al. (2010), the expiratory lengthening induced by arterial baroreceptor activation results from the activation of post-inspiratory neurons of the BötC, which, in turn, inhibit the central inspiratory activity (Smith et al., 2007). Since these post-inspiratory neurons may also establish synaptic contacts with the pre-sympathetic neurons of the RVLM (Sun et al., 1997), the baroreflex-induced activation of inhibitory post-inspiratory neurons of the BötC may additionally contribute to depress the RVLM neuronal activity (Baekey et al., 2010). Besides, with the post-inspiratory activation and the increase in expiratory time, the emergence of inspiratory-related bursts of sympathetic activity is delayed and the sympathetic activity is maintained at low levels. Therefore, in addition to the classical NTS-CVLM-RVLM baroreflex arc, a parallel respiratory-dependent pathway from the NTS to the VRC also contributes to reduce sympathetic activity in conditions of high arterial pressure. It remains to be elucidated whether this respiratory baroreflex pathway relies on the different subset of 2nd-order neurons (for instance, neurons receiving SAR afferent information, as described below) or recruits neurotransmitter other than L-glutamate (Machado et al., 2000; Baekey et al., 2010).
Mechanoreceptors located mainly in pulmonary walls, including the SARs and RARs, are important to reflexly control the central respiratory command according to lung volume (for further review, see Kubin et al., 2006). Although both receptors are sensitive to pulmonary wall distension, the lung inflation feedback control is evoked mainly by SAR afferent inputs (Bonham et al., 1993). The vagal afferents from SARs terminates predominantly in the ventrolateral portion of the iNTS (Kalia and Mesulam, 1980). In rats, different populations of neurons are suggested to receive the afferent information from SARs: (i) inspiratory neurons that fire during central inspiratory drive and are sensitive to vagal stimulation (either excited or inhibited); (ii) pump cells ( $\mathrm{P}$ cells) that present action potentials in phase with lung inflation cycle, but not with central inspiratory rhythm, and are activated when lungs are overinflated (Bonham and McCrimmon, 1990; De Castro et al., 1994). SARs stimulation initiates the HeringBreuer reflex and promotes the suppression of inspiratory motor activity and prolongs the expiratory phase (Breuer, 1868; Hering, 1868; Backman et al., 1984; Kubin et al., 2006). The removal of pulmonary feedback control, through vagotomy, results in large increases of inspiratory amplitude and duration (Kubin et al., 2006), evidencing an important role of the SARs feedback information for baseline control of respiratory phase transition and duration.

$\mathrm{P}$ cells of the iNTS are thought to be the main cellular source integrating and transmitting the SAR afferent information to pontine and medullary respiratory neurons (McCrimmon et al., 1987; Bonham et al., 1993; Ezure et al., 2002; Molkov et al., 2013), leading to the activation of the post-inspiratory neurons of the BötC that, in turn, inhibit the inspiratory neuronal activity (Hayashi et al., 1996). By the fact that the antagonism of ionotropic glutamatergic receptors in the iNTS of anesthetized animals greatly attenuates baseline activity of $\mathrm{P}$ cells and impairs the Hering-Breuer respiratory reflex responses (Bonham and McCrimmon, 1990; Bonham et al., 1993), it has been suggested that L-glutamate is the major neurotransmitter release by SAR vagal afferent in the iNTS. Microinjections of glutamatergic agonists into the iNTS excite $\mathrm{P}$ cells and promote apnea and expiratory lengthening like Hering-Breuer reflex (Bonham et al., 1993; Gourine et al., 2008), corroborating the idea that L-glutamate is released by SAR afferent inputs in the iNTS. In addition to L-glutamate, there is evidence that other neurotransmitters may play a role in the processing of pulmonary afferent information at the level of iNTS. Studies by Gourine et al. (2008) demonstrated that the concentrations of ATP and L-glutamate in the iNTS increase in phase to lung inflation and independently on central respiratory drive, suggesting that SAR afferents may release both neurotransmitters. Also, injections of ATP in the iNTS mimic the respiratory responses induced by lung inflation (Antunes et al., 2005; Gourine et al., 2008) and the antagonism of purinergic receptors significantly reduced basal activity of $\mathrm{P}$ cells (Gourine et al., 2008). These results suggest that an interaction between glutamatergic and purinergic systems may mediate the processing of pulmonary feedback information at the level of iNTS.

Lung inflation also elicits a decrease in sympathetic activity and vasodilation in addition to the respiratory responses (Gerber and Polosa, 1978; Sellden et al., 1987; Yu et al., 1990), suggesting 
a possible correlation between the respiratory and sympathetic responses to SAR activation. Since L-glutamate is suggested to be the major neurotransmitter release by SAR afferents (Bonham et al., 1993), it is possible to speculate that glutamatergic activation of $\mathrm{P}$ cells also mediates the reduction of sympathetic activity associated with expiratory prolongation. In agreement with that, studies have demonstrated that microinjections of L-glutamate in the iNTS produce coupled inspiratory inhibition, expiratory lengthening and sympatho-inhibition (Berger et al., 1995; Marchenko and Sapru, 2000). Alternatively, it is possible that the sympathetic and inspiratory inhibitory responses to lung inflation rely on interactions with neurons that are part of the baroreflex pathway, which are also located in the iNTS and are activated by L-glutamate (Bailey et al., 2006). Both possibilities, although not proven experimentally, indicate that the iNTS possesses a complex neuronal circuitry that is important to coupled respiratory and sympathetic responses to cardiorespiratory mechanoreceptor activation.

We recently verified that microinjections of ACh in the iNTS reduce phrenic burst frequency, due to an increase in expiratory time, associated with reductions in sympathetic activity (Furuya et al., 2014). Interestingly, this cholinergic system of the iNTS apparently is not involved in the processing of the baroreflex responses because the antagonism of cholinergic receptors in the iNTS did not prevent the sympathetic and respiratory responses elicited by increase in pressure (Furuya et al., 2014). These findings suggest that the cholinergic neurotransmission in the iNTS may also contribute to the processing of respiratory and sympathetic responses of Hering-Breuer reflex. Nonetheless, this possibility still requires further experiments to be proven.

Therefore, the respiratory and sympathetic changes induced by Hering-Breuer activation may involve the release/co-release of distinct neurotransmitters, which may interact and activate either excitatory or inhibitory $\mathrm{P}$ cells (Kubin et al., 2006) or different neuronal populations ( $\mathrm{P}$ cells and baroreflex sensitive neurons) within the iNTS.

\section{NTS NEUROPLASTICITY AND THE DEVELOPMENT OF CARDIORESPIRATORY DYSFUNCTIONS}

In response to intensive stimuli, the afferents and neurons of the NTS may exhibit plastic changes (Zhou et al., 1997; Chen et al., 1999; Kline, 2008) that, in turn, modify the control of respiratory and sympathetic activities. Depending on the degree of plasticity, the changes in the NTS neuronal activity may persist and contribute to the development and/or maintenance of cardiorespiratory dysfunctions. This may be the case of pathological conditions associated with potentiation of peripheral chemoreflex responses and sympathetic overactivity (Narkiewicz et al., 1998; Niewinski et al., 2013). Therefore, the understanding of the mechanisms promoting plastic changes in the NTS circuitry associated with pathological conditions may help to develop potential therapeutic venues to treat cardiorespiratory diseases, as discussed below.

\section{NEUROGENIC HYPERTENSION}

There is compelling evidence indicating that hyperactivity of the sympathetic nervous system is an important mechanism producing the chronic elevation of arterial pressure in hypertensive patients (Staessen et al., 2003), especially those that are resistant to concurrent anti-hypertensive treatment (Esler, 2012). Recent studies indicate that the surgical removal of the carotid body peripheral chemoreceptors of juvenile (4-week old) spontaneous hypertensive rats (SHR), an experimental model for neurogenic hypertension, attenuates the development of hypertension (Abdala et al., 2012). In adult SHR rats (12-week old), the carotid body denervation significantly reduces arterial pressure and renal sympathetic nerve activity levels (McBryde et al., 2013). The high levels of sympathetic activity in SHRs exhibit an amplified respiratory-sympathetic coupling, with augmented sympathetic activity mainly during the inspiratory phase (Czyzyk-Krzeska and Trzebski, 1990; Simms et al., 2009) that is also reduced with the removal of carotid body chemoreceptors (McBryde et al., 2013). Based on that, it has been proposed that heightened peripheral chemoreceptor activity contributes to elevate baseline levels of sympathetic activity and magnify the respiratory modulation of sympathetic activity in SHR rats. Studies by Sato et al. (2001) have shown that lesions of the cNTS also produce a significant fall in the arterial pressure level in adult SHR, but not in normotensive rats, suggesting that the development of hypertension in this model may involve neuroplasticity within the NTS. In agreement with this hypothesis, there are several studies demonstrating relevant changes in the mechanisms of neurotransmission and neuromodulation in the NTS of SHR rats, including glutamate (Aicher et al., 2003), angiontesin II (Shan et al., 2013), GABA (Mei et al., 2003; Spary et al., 2008), nitric oxide (Hirooka et al., 2003) and inflammatory molecules (Waki et al., 2008). Altogether, these findings indicate that neurogenic hypertension is causally associated with potentiation of peripheral chemoreflex, in which plastic changes of cNTS neurons receiving the afferent inputs from the carotid bodies importantly contribute to elevate baseline sympathetic activity and strength respiratory-sympathetic coupling. The contribution of amplified respiratory-sympathetic coupling for the development and maintenance of arterial hypertension in SHR rats is still under investigation and is matter of debate (Fatouleh and Macefield, 2011; Moraes et al., 2014).

\section{CHRONIC INTERMITTENT HYPOXIA}

Sensitization of the peripheral chemoreflex is observed in patients suffering obstructive sleep apnea (OSA). Due to recurrent collapses of upper airways, OSA patients frequently experience intermittent episodes of hypoxia during sleep (Dempsey et al., 2010). Overtime, untreated OSA patients develop arterial hypertension associated with high levels of sympathetic activity (Somers, 1995) and tonic chemoreflex activation (Narkiewicz et al., 1998). In rodent models, the exposure to chronic intermittent hypoxia $(\mathrm{CIH})$ causes a sustained increase in baseline arterial pressure that is prevented by carotid body denervation (Fletcher et al., 1992). The hypertension induced by CIH in rats is associated with high levels of baseline sympathetic activity (Zoccal et al., 2007, 2008, 2009), enhanced baseline frequency of discharge of RVLM pre-sympathetic neurons (Moraes et al., 2013), augmented peripheral chemoreflex responses (Peng et al., 2003; Rey et al., 2004; Braga et al., 2006), changes in the respiratory pattern and strengthened respiratory-sympathetic coupling (Zoccal 
et al., 2008). Therefore, intermittent activation of the peripheral chemoreceptors, as observed in OSA patients, introduces persistent changes in the neural pathways of peripheral chemoreflex that culminate with the development of cardiorespiratory dysfunctions.

With respect to the NTS, studies in vitro evidenced that AMPAevoked currents of isolated 2nd-order neurons of the cNTS are enhanced in rats exposed to CIH (De Paula et al., 2007). Our previous studies demonstrated that $\mathrm{CIH}$ rats exhibit augmented sympatho-excitatory and blunted phrenic apneic responses to microinjections of L-glutamate in the cNTS in association with increased densities of NMDA and non-NMDA receptor subunities within the cNTS (Costa-Silva et al., 2012). Altogether, these studies indicate that $\mathrm{CIH}$ exposure promotes functional changes in the glutamatergic neurontrasmission in the cNTS. In addition to the glutamatergic mechanisms, Zhang et al. (2008) reported that the outward currents mediated by ATP-sensitive potassium channels $\left(\mathrm{K}_{\mathrm{ATP}}\right)$ of 2 nd-order neurons of the peripheral chemoreceptors of $\mathrm{CIH}$ rats are reduced-a fact that may increase the excitability of these neurons. Accordingly, $\mathrm{CIH}$ exposure appears to alter post-synaptic mechanisms in neurons of the cNTS, amplifying the excitatory responses to glutamatergic receptor activation.

Kline et al. (2007) have also documented that neurons of the cNTS of rats submitted to CIH exhibit a higher basal frequency of discharge due to an augmented spontaneous neurotransmitter release by pre-synaptic terminals. Therefore, increased spontaneous neurotransmitter release combined with amplified post-synaptic glutamatergic excitatory responses may represent an important mechanism producing enhanced basal and evoked activity of cNTS neurons after CIH. As a consequence, higher excitatory drive is transmitted to downstream sympathetic and respiratory chemoreflex pathways, which contribute, at least in part, to the development of cardiorespiratory dysfunctions associated with $\mathrm{CIH}$ exposure. So far, there are no studies elucidating the involvement of other neurotransmitters or neuromodulators of the cNTS (for instance ATP or ACh) in the context of CIH. This represents important possibilities to better understand the contribution of the cNTS mechanisms to elevate baseline sympathetic activity or modify the respiratory pattern and the respiratorysympathetic coupling in CIH rats, since the overactivity of RVLM pre-sympathetic neurons induced by $\mathrm{CIH}$ mainly depends on synaptic inputs rather than changes in their intrinsic properties (Moraes et al., 2013).

\section{OBESITY}

Additionally to the classical neurochemical mechanisms, there is evidence that peripheral molecules interfere with the activity of the NTS neurons and then modify sympathetic and respiratory activities. This peripheral-central crosstalk appears to have significance in the context of the cardiovascular dysfunctions related to obesity. Obese individuals may develop arterial hypertension associated with high levels of sympathetic activity (Hall et al., 2010), by mechanisms not completely understood. Adipocytes are considered as an endocrine tissue producing several substances including interleukin-6, tumor necrosis factors- $\alpha$, adiponectin and leptin (Kershaw and Flier, 2004; Galic et al., 2010). Attention has been given to the effects of leptin on the central mechanisms controlling autonomic and respiratory activities. In addition to its central effects suppressing appetite (Grill, 2006), it was shown that leptin exerts excitatory effects on central nuclei controlling sympathetic (Rahmouni et al., 2005; Mark et al., 2009) and respiratory activities (Inyushkina et al., 2010; Malli et al., 2010; Bassi et al., 2012, 2014; Chang et al., 2013), increasing baseline sympathetic activity and stimulating breathing. By the fact that leptin levels are enhanced in obese subjects (Considine et al., 1996), this hormone can be considered as a relevant candidate acting on central nervous system and contributing to the cardiovascular changes associated with obesity.

Systemic administration of leptin has been shown to increase c-fos expression in neurons of the cNTS (Elmquist et al., 1998; Elias et al., 2000) and enhance phrenic burst amplitude (Chang et al., 2013). Morevoer, microinjections of leptin in the NTS increase renal sympathetic activity (Mark et al., 2009) and ventilation (Inyushkin et al., 2009). Therefore, the NTS is a potential target for action of circulating leptin. Importantly, both obesity and high leptin levels have been observed in OSA patients, who present a high risk to develop arterial hypertension than nonobese OSA patients (Schafer et al., 2002; Harsch et al., 2003; Patel et al., 2004). Therefore, a positive interaction between intermittent hypoxia, peripheral chemoreflex activation and leptin effects may be considered. In this regard, it was reported that the sympatho-excitatory responses induced by either activation of peripheral chemoreceptors or microinjections of L-glutamate in the cNTS are potentiated by previous microinjections of leptin in the cNTS (Ciriello and Moreau, 2012). Thus leptin enhances the sympatho-excitatory responses to peripheral chemoreflex activation through its actions on cNTS neurons involved with the processing of peripheral chemoreceptor inputs. The effects of leptin on the chemoreflex-induced respiratory response and on respiratory-sympathetic coupling are still to be determined.

\section{CONCLUDING REMARKS}

Although the precise physiological meaning of the respiratorysympathetic coupling in different conditions (resting, metabolic challenges and physical exercise) is still under debate (Hayano et al., 1996; Ben-Tal et al., 2012), there is evidence showing that modifications in the central mechanisms underlying the interactions between respiratory and sympathetic neurons are associated with the development of sympathetic overactivity (Zoccal et al., 2008; Simms et al., 2009; Toney et al., 2010). In this regard, the identification of neuronal sources and targets as well as the corresponding neurochemical mechanisms underlying the respiratorysympathetic coupling is required for a better comprehension of this phenomenon and its pathological implications. In addition to ventral medullary neurons, the NTS neurons play an essential role in coordinating respiratory and sympathetic adjustments in response to activation of peripheral cardiovascular and pulmonary afferent inputs, such as the baroreceptors, the pulmonary stretch receptors and especially the peripheral chemoreceptors. Due to its afferent-based organization, neurons of specific subregions of the NTS may respond to different stimuli and generate specific patterns of responses due to the recruitment of specific downstream sympathetic and respiratory pathways. 


\section{AUTHOR CONTRIBUTIONS}

Daniel B. Zoccal designed the manuscript. Daniel B. Zoccal, Werner I. Furuya, Mirian Bassi, Débora S. A. Colombari and Eduardo Colombari drafted and revised the manuscript. Daniel B. Zoccal prepared the figures. All authors approved the final version of the manuscript.

\section{ACKNOWLEDGMENTS}

The research was supported by Fundação de Amparo a Pesquisa do Estado de São Paulo (FAPESP, grants 2009/548887, 2009/53205-3 and 2011/20040-1) and Conselho Nacional de Desenvolvimento Científico e Tecnológico (CNPq, grant 478640/2013-7).

\section{REFERENCES}

Abdala, A. P., McBryde, F. D., Marina, N., Hendy, E. B., Engelman, Z. J., Fudim, M., et al. (2012). Hypertension is critically dependent on the carotid body input in the spontaneously hypertensive rat. J. Physiol. 590, 4269-4277. doi: 10.1113/jphysiol.2012.237800

Accorsi-Mendonca, D., Bonagamba, L. G., Leao, R. M., and Machado, B. H. (2009). Are L-glutamate and ATP cotransmitters of the peripheral chemoreflex in the rat nucleus tractus solitarius? Exp. Physiol. 94, 38-45. doi: expphysiol.2008.043653

Accorsi-Mendonca, D., Castania, J. A., Bonagamba, L. G., Machado, B. H., and Leao, R. M. (2011). Synaptic profile of nucleus tractus solitarius neurons involved with the peripheral chemoreflex pathways. Neuroscience 197, 107-120. doi: 10.1016/j.neuroscience.2011.08.054

Accorsi-Mendonca, D., Zoccal, D. B., Bonagamba, L. G., and Machado, B. H. (2013). Glial cells modulate the synaptic transmission of NTS neurons sending projections to ventral medulla of Wistar rats. Physiol. Rep. 1:e00080. doi: 10.1002/phy2.80

Adrian, E. D., Bronk, D. W., and Phillips, G. (1932). Discharges in mammalian sympathetic nerves. J. Physiol. 74, 115-133.

Aicher, S. A., Kurucz, O. S., Reis, D. J., and Milner, T. A. (1995). Nucleus tractus solitarius efferent terminals synapse on neurons in the caudal ventrolateral medulla that project to the rostral ventrolateral medulla. Brain Res. 693, 51-63. doi: 10.1016/0006-8993(95)00660-I

Aicher, S. A., Saravay, R. H., Cravo, S., Jeske, I., Morrison, S. F., Reis, D. J., et al. (1996). Monosynaptic projections from the nucleus tractus solitarii to $\mathrm{C} 1$ adrenergic neurons in the rostral ventrolateral medulla: comparison with input from the caudal ventrolateral medulla. J. Comp. Neurol. 373, 62-75. doi: 10.1002/(SICI) 1096-9861(19960909)373:1<62::AID-CNE6>3.0.CO;2-B

Aicher, S. A., Sharma, S., and Mitchell, J. L. (2003). Structural changes in AMPA-receptive neurons in the nucleus of the solitary tract of spontaneously hypertensive rats. Hypertension 41, 1246-1252. doi: 10.1161/01.HYP.0000069007.98987.E0

Alheid, G. F., Jiao, W., and McCrimmon, D. R. (2011). Caudal nuclei of the rat nucleus of the solitary tract differentially innervate respiratory compartments within the ventrolateral medulla. Neuroscience 190, 207-227. doi: 10.1016/j.neuroscience.2011.06.005

Almado, C. E., Machado, B. H., and Leao, R. M. (2012). Chronic intermittent hypoxia depresses afferent neurotransmission in NTS neurons by a reduction in the number of active synapses. J. Neurosci. 32, 16736-16746. doi: 10.1523/JNEUROSCI.2654-12.2012

Andresen, M. C., and Kunze, D. L. (1994). Nucleus tractus solitariusgateway to neural circulatory control. Annu. Rev. Physiol. 56, 93-116. doi: 10.1146/annurev.ph.56.030194.000521

Andresen, M. C., and Yang, M. Y. (1990). Non-NMDA receptors mediate sensory afferent synaptic transmission in medial nucleus tractus solitarius. Am. J. Physiol. 259, H1307-H1311.

Antunes, V. R., Bonagamba, L. G., and Machado, B. H. (2005). Hemodynamic and respiratory responses to microinjection of ATP into the intermediate and caudal NTS of awake rats. Brain Res. 1032, 85-93. doi: 10.1016/j.brainres.2004.10.048

Backman, S. B., Anders, C., Ballantyne, D., Rohrig, N., Camerer, H., Mifflin, S., et al. (1984). Evidence for a monosynaptic connection between slowly adapting pulmonary stretch receptor afferents and inspiratory beta neurones. Pflugers Arch. 402, 129-136. doi: 10.1007/BF00583324
Baekey, D. M., Dick, T. E., and Paton, J. F. (2008). Pontomedullary transection attenuates central respiratory modulation of sympathetic discharge, heart rate and the baroreceptor reflex in the in situ rat preparation. Exp. Physiol. 93, 803-816. doi: 10.1113/expphysiol.2007.041400

Baekey, D. M., Molkov, Y. I., Paton, J. F., Rybak, I. A., and Dick, T. E. (2010). Effect of baroreceptor stimulation on the respiratory pattern: insights into respiratory-sympathetic interactions. Respir. Physiol. Neurobiol. 174, 135-145. doi: 10.1016/j.resp.2010.09.006

Bailey, T. W., Hermes, S. M., Andresen, M. C., and Aicher, S. A. (2006). Cranial visceral afferent pathways through the nucleus of the solitary tract to caudal ventrolateral medulla or paraventricular hypothalamus: target-specific synaptic reliability and convergence patterns. J. Neurosci. 26, 11893-11902. doi: 10.1523/JNEUROSCI.2044-06.2006

Barman, S. M., and Gebber, G. L. (1980). Sympathetic nerve rhythm of brain stem origin. Am. J. Physiol. 239, R42-R47.

Barman, S. M., and Gebber, G. L. (2000). "Rapid" rhythmic discharges of sympathetic nerves: sources, mechanisms of generation, and physiological Relevance. J. Biol. Rhythms 15, 365-379. doi: 10.1177/074873000129001468

Bassi, M., Furuya, W. I., Menani, J. V., Colombari, D. S., Do Carmo, J. M., Da Silva, A. A., et al. (2014). Leptin into the ventrolateral medulla facilitates chemorespiratory response in leptin-deficient (ob/ob) mice. Acta Physiol. (Oxf). 211, 240-248. doi: 10.1111/apha.12257

Bassi, M., Giusti, H., Leite, C. M., Anselmo-Franci, J. A., Do Carmo, J. M., Da Silva, A. A., et al. (2012). Central leptin replacement enhances chemorespiratory responses in leptin-deficient mice independent of changes in body weight. Pflugers Arch. 464, 145-153. doi: 10.1007/s00424-012-1111-1

Ben-Tal, A., Shamailov, S. S., and Paton, J. F. (2012). Evaluating the physiological significance of respiratory sinus arrhythmia: looking beyond ventilation-perfusion efficiency. J. Physiol. 590, 1989-2008. doi: 10.1113/jphysiol.2011.222422

Berger, I., Gillis, R. A., Vitagliano, S., Panico, W. H., Magee, S., Kelly, M., et al. (1995). NMDA receptors are involved at the ventrolateral nucleus tractus solitarii for termination of inspiration. Eur. J. Pharmacol. 277, 195-208. doi: 10.1016/0014-2999(95)00073-T

Bernardi, L., Porta, C., Gabutti, A., Spicuzza, L., and Sleight, P. (2001). Modulatory effects of respiration. Auton. Neurosci. 90, 47-56. doi: 10.1016/S15660702(01)00267-3

Bianchi, A. L., Denavit-Saubie, M., and Champagnat, J. (1995). Central control of breathing in mammals: neuronal circuitry, membrane properties, and neurotransmitters. Physiol. Rev. 75, 1-45.

Boczek-Funcke, A., Dembowsky, K., Habler, H. J., Janig, W., and Michaelis, M. (1992). Respiratory-related activity patterns in preganglionic neurones projecting into the cat cervical sympathetic trunk. J. Physiol. 457, 277-296.

Bonham, A. C., Coles, S. K., and McCrimmon, D. R. (1993). Pulmonary stretch receptor afferents activate excitatory amino acid receptors in the nucleus tractus solitarii in rats. J. Physiol. 464, 725-745.

Bonham, A. C., and McCrimmon, D. R. (1990). Neurones in a discrete region of the nucleus tractus solitarius are required for the Breuer-Hering reflex in rat. J. Physiol. 427, 261-280.

Bouairi, E., Neff, R., Evans, C., Gold, A., Andresen, M. C., and Mendelowitz, D. (2004). Respiratory sinus arrhythmia in freely moving and anesthetized rats. J. Appl. Physiol. 97, 1431-1436. doi: 10.1152/japplphysiol.00277.2004

Braccialli, A. L., Bonagamba, L. G., and Machado, B. H. (2008). Glutamatergic and purinergic mechanisms on respiratory modulation in the caudal NTS of awake rats. Respir. Physiol. Neurobiol. 161, 246-252. doi: 10.1016/j.resp.2008.02.011

Braga, V. A., and Machado, B. H. (2006). Chemoreflex sympathoexcitation was not altered by the antagonism of glutamate receptors in the commissural nucleus tractus solitarii in the working heart-brainstem preparation of rats. Exp. Physiol. 91, 551-559. doi: 10.1113/expphysiol.2005.033100

Braga, V. A., Soriano, R. N., Braccialli, A. L., De Paula, P. M., Bonagamba, L. G. Paton, J. F., et al. (2007). Involvement of L-glutamate and ATP in the neurotransmission of the sympathoexcitatory component of the chemoreflex in the commissural nucleus tractus solitarii of awake rats and in the working heart-brainstem preparation. J. Physiol. 581, 1129-1145. doi: 10.1113/jphysiol.2007.129031

Braga, V. A., Soriano, R. N., and Machado, B. H. (2006). Sympathoexcitatory response to peripheral chemoreflex activation is enhanced in juvenile rats exposed to chronic intermittent hypoxia. Exp. Physiol. 91, 1025-1031. doi: 10.1113/expphysiol.2006.034868 
Breuer, J. (1868). Die selbststeurung der athmung durch nervus vagus. Akad. Wiss. Wien (II) 58, 909-937.

Chan, R. K., and Sawchenko, P. E. (1998). Organization and transmitter specificity of medullary neurons activated by sustained hypertension: implications for understanding baroreceptor reflex circuitry. J. Neurosci. 18, 371-387.

Chang, Z., Ballou, E., Jiao, W., McKenna, K. E., Morrison, S. F., and McCrimmon, D. R. (2013). Systemic leptin produces a long-lasting increase in respiratory motor output in rats. Front. Physiol. 4:16. doi: 10.3389/fphys.2013. 00016

Chen, C. Y., Horowitz, J. M., and Bonham, A. C. (1999). A presynaptic mechanism contributes to depression of autonomic signal transmission in NTS. Am. J. Physiol. 277, H1350-H1360.

Ciriello, J., and Moreau, J. M. (2012). Leptin signaling in the nucleus of the solitary tract alters the cardiovascular responses to activation of the chemoreceptor reflex. Am. J. Physiol. Regul. Integr. Comp. Physiol. 303, R727-R736. doi 10.1152/ajpregu.00068.2012

Colombari, E., Menani, J. V., and Talman, W. T. (1996). Commissural NTS contributes to pressor responses to glutamate injected into the medial NTS of awake rats. Am. J. Physiol. 270, R1220-R1225.

Considine, R. V., Sinha, M. K., Heiman, M. L., Kriauciunas, A., Stephens, T. W., Nyce, M. R., et al. (1996). Serum immunoreactive-leptin concentrations in normal-weight and obese humans. N. Engl. J. Med. 334, 292-295. doi: 10.1056/NEJM199602013340503

Costa-Silva, J. H., Zoccal, D. B., and Machado, B. H. (2010). Glutamatergic antagonism in the NTS decreases post-inspiratory drive and changes phrenic and sympathetic coupling during chemoreflex activation. J. Neurophysiol. 103, 2095-2106. doi: 10.1152/jn.00802.2009

Costa-Silva, J. H., Zoccal, D. B., and Machado, B. H. (2012). Chronic intermittent hypoxia alters glutamatergic control of sympathetic and respiratory activities in the commissural NTS of rats. Am. J. Physiol. Regul. Integr. Comp. Physiol. 302, R785-R793. doi: 10.1152/ajpregu.00363.2011

Cruz, J. C., Bonagamba, L. G., Stern, J. E., and Machado, B. H. (2010). Fos expression in the NTS in response to peripheral chemoreflex activation in awake rats. Auton. Neurosci. 152, 27-34. doi: 10.1016/j.autneu.2009.08.016

Czyzyk-Krzeska, M. F., and Trzebski, A. (1990). Respiratory-related discharge pattern of sympathetic nerve activity in the spontaneously hypertensive rat. J. Physiol. 426, 355-368.

Dampney, R. A. (1994). Functional organization of central pathways regulating the cardiovascular system. Physiol. Rev. 74, 323-364.

De Castro, D., Lipski, J., and Kanjhan, R. (1994). Electrophysiological study of dorsal respiratory neurons in the medulla oblongata of the rat. Brain Res. 639, 49-56. doi: 10.1016/0006-8993(94)91763-9

Dempsey, J. A., Veasey, S. C., Morgan, B. J., and O'Donnell, C. P. (2010). Pathophysiology of sleep apnea. Physiol. Rev. 90, 47-112. doi: 10.1152/physrev.00043.2008

De Paula, P. M., Tolstykh, G., and Mifflin, S. (2007). Chronic intermittent hypoxia alters NMDA and AMPA-evoked currents in NTS neurons receiving carotid body chemoreceptor inputs. Am. J. Physiol. Regul. Integr. Comp. Physiol. 292, R2259-R2265. doi: 10.1152/ajpregu.00760.2006

Dick, T. E., Hsieh, Y. H., Morrison, S., Coles, S. K., and Prabhakar, N. (2004). Entrainment pattern between sympathetic and phrenic nerve activities in the Sprague-Dawley rat: hypoxia-evoked sympathetic activity during expiration. Am. J. Physiol. Regul. Integr. Comp. Physiol. 286, R1121-R1128. doi: 10.1152/ajpregu.00485.2003

Dobbins, E. G., and Feldman, J. L. (1994). Brainstem network controlling descending drive to phrenic motoneurons in rat. J. Comp. Neurol. 347, 64-86. doi: $10.1002 / \mathrm{cne} .903470106$

Doyle, M. W., Bailey, T. W., Jin, Y. H., Appleyard, S. M., Low, M. J., and Andresen, M. C. (2004). Strategies for cellular identification in nucleus tractus solitarius slices. J. Neurosci. Methods 137, 37-48. doi: 10.1016/j.jneumeth.2004.02.007

Elias, C. F., Kelly, J. F., Lee, C. E., Ahima, R. S., Drucker, D. J., Saper, C. B., et al. (2000). Chemical characterization of leptin-activated neurons in the rat brain. J. Comp. Neurol. 423, 261-281. doi: 10.1002/10969861(20000724)423:2\%3C261::AID-CNE6\%3E3.3.CO;2-Y

Elmquist, J. K., Bjorbaek, C., Ahima, R. S., Flier, J. S., and Saper, C. B. (1998). Distributions of leptin receptor mRNA isoforms in the rat brain. J. Comp. Neurol. 395, 535-547. doi: 10.1002/(SICI)10969861(19980615)395:4<535::AID-CNE9>3.0.CO;2-2
Esler, M. (2012). The sympathetic nervous system through the ages: from Thomas Willis to resistant hypertension. Exp. Physiol. 96, 611-622. doi: 10.1113/expphysiol.2010.052332

Ezure, K., Tanaka, I., Saito, Y., and Otake, K. (2002). Axonal projections of pulmonary slowly adapting receptor relay neurons in the rat. J. Comp. Neurol. 446, 81-94. doi: 10.1002/cne.10185

Fatouleh, R., and Macefield, V. G. (2011). Respiratory modulation of muscle sympathetic nerve activity is not increased in essential hypertension or chronic obstructive pulmonary disease. J. Physiol. 589, 4997-5006. doi: 10.1113/jphysiol.2011.210534

Fletcher, E. C., Lesske, J., Behm, R., Miller, C. C. 3rd, Stauss, H., and Unger, T. (1992). Carotid chemoreceptors, systemic blood pressure, and chronic episodic hypoxia mimicking sleep apnea. J. Appl. Physiol. 72, 1978-1984.

Furuya, W. I., Bassi, M., Menani, J. V., Colombari, E., Zoccal, D. B., and Colombari, D. S. (2014). Differential modulation of sympathetic and respiratory activities by cholinergic mechanisms in the nucleus of the solitary tract in rats. Exp. Physiol. 99, 743-758. doi: 10.1113/expphysiol.2013.076794

Galic, S., Oakhill, J. S., and Steinberg, G. R. (2010). Adipose tissue as an endocrine organ. Mol. Cell. Endocrinol. 316, 129-139. doi: 10.1016/j.mce.2009.08.018

Gerber, U., and Polosa, C. (1978). Effects of pulmonary stretch receptor afferent stimulation on sympathetic preganglionic neuron firing. Can. J. Physiol Pharmacol. 56, 191-198. doi: 10.1139/y78-027

Giardino, N. D., Glenny, R. W., Borson, S., and Chan, L. (2003). Respiratory sinus arrhythmia is associated with efficiency of pulmonary gas exchange in healthy humans. Am. J. Physiol. Heart Circ. Physiol. 284, H1585-H1591. doi: 10.1152/ajpheart.00893.2002

Gilbey, M. P. (2007). Sympathetic rhythms and nervous integration. Clin. Exp. Pharmacol. Physiol. 34, 356-361. doi: 10.1111/j.1440-1681.2007.04587.x

Gordon, F. J., and Sved, A. F. (2002). Neurotransmitters in central cardiovascular regulation: glutamate and GABA. Clin. Exp. Pharmacol. Physiol. 29, 522-524. doi: 10.1046/j.1440-1681.2002.03666.x

Gourine, A. V., Dale, N., Korsak, A., Llaudet, E., Tian, F., Huckstepp, R., et al. (2008). Release of ATP and glutamate in the nucleus tractus solitarii mediate pulmonary stretch receptor (Breuer-Hering) reflex pathway. J. Physiol. 586, 3963-3978. doi: 10.1113/jphysiol.2008.154567

Gozal, D., Xue, Y. D., and Simakajornboon, N. (1999). Hypoxia induces c-Fos protein expression in NMDA but not AMPA glutamate receptor labeled neurons within the nucleus tractus solitarii of the conscious rat. Neurosci. Lett. 262, 93-96. doi: 10.1016/S0304-3940(99)00065-8

Grill, H. J. (2006). Distributed neural control of energy balance: contributions from hindbrain and hypothalamus. Obesity (Silver Spring) 14(Suppl. 5), 216S-221S. doi: 10.1038/oby.2006.312

Grill, H. J., and Hayes, M. R. (2009). The nucleus tractus solitarius: a portal for visceral afferent signal processing, energy status assessment and integration of their combined effects on food intake. Int. J. Obes. 33, S11-S15. doi: 10.1038/ijo.2009.10

Grossman, P., and Taylor, E. W. (2007). Toward understanding respiratory sinus arrhythmia: relations to cardiac vagal tone, evolution and biobehavioral functions. Biol. Psychol. 74, 263-285. doi: 10.1016/j.biopsycho.2005.11.014

Guertzenstein, P. G., and Silver, A. (1974). Fall in blood pressure produced from discrete regions of the ventral surface of the medulla by glycine and lesions. J. Physiol. 242, 489-503.

Haibara, A. S., Colombari, E., Chianca, D. A. Jr., Bonagamba, L. G., and Machado, B. H. (1995). NMDA receptors in NTS are involved in bradycardic but not in pressor response of chemoreflex. Am. J. Physiol. 269, H1421-H1427.

Haibara, A. S., Tamashiro, E., Olivan, M. V., Bonagamba, L. G., and Machado, B. H. (2002). Involvement of the parabrachial nucleus in the pressor response to chemoreflex activation in awake rats. Auton. Neurosci. 101, 60-67. doi: 10.1016/S1566-0702(02)00210-2

Hall, J. E., Da Silva, A. A., Do Carmo, J. M., Dubinion, J., Hamza, S., Munusamy, S., et al. (2010). Obesity-induced hypertension: role of sympathetic nervous system, leptin, and melanocortins. J. Biol. Chem. 285, 17271-17276. doi: 10.1074/jbc.R110.113175

Harsch, I. A., Konturek, P. C., Koebnick, C., Kuehnlein, P. P., Fuchs, F. S., Pour Schahin, S., et al. (2003). Leptin and ghrelin levels in patients with obstructive sleep apnoea: effect of CPAP treatment. Eur. Respir. J. 22, 251-257. doi: $10.1183 / 09031936.03 .00010103$

Haselton, J. R., and Guyenet, P. G. (1989). Central respiratory modulation of medullary sympathoexcitatory neurons in rat. Am. J. Physiol. 256, R739-R750. 
Hayano, J., Yasuma, F., Okada, A., Mukai, S., and Fujinami, T. (1996). Respiratory sinus arrhythmia. A phenomenon improving pulmonary gas exchange and circulatory efficiency. Circulation 94, 842-847. doi: 10.1161/01.CIR.94.4.842

Hayashi, F., Coles, S. K., and McCrimmon, D. R. (1996). Respiratory neurons mediating the Breuer-Hering reflex prolongation of expiration in rat. J. Neurosci. 16 , 6526-6536.

Hering, E. (1868). Die selbststeurung der athmung durch den nervus vagus. Akad. Wiss. Wien (II) 58, 672-677.

Hirooka, Y., Sakai, K., Kishi, T., Ito, K., Shimokawa, H., and Takeshita, A. (2003). Enhanced depressor response to endothelial nitric oxide synthase gene transfer into the nucleus tractus solitarii of spontaneously hypertensive rats. Hypertens. Res. 26, 325-331. doi: 10.1291/hypres.26.325

Inyushkin, A. N., Inyushkina, E. M., and Merkulova, N. A. (2009). Respiratory responses to microinjections of leptin into the solitary tract nucleus. Neurosci. Behav. Physiol. 39, 231-240. doi: 10.1007/s11055-009-9124-8

Inyushkina, E. M., Merkulova, N. A., and Inyushkin, A. N. (2010). Mechanisms of the respiratory activity of leptin at the level of the solitary tract nucleus. Neurosci. Behav. Physiol. 40, 707-713. doi: 10.1007/s11055-010-9316-2

Johnson, A. K., and Thunhorst, R. L. (1997). The neuroendocrinology of thirst and salt appetite: visceral sensory signals and mechanisms of central integration. Front. Neuroendocrinol. 18, 292-353. doi: 10.1006/frne.1997.0153

Kalia, M., and Mesulam, M. M. (1980). Brain stem projections of sensory and motor components of the vagus complex in the cat: II. Laryngeal, tracheobronchial, pulmonary, cardiac, and gastrointestinal branches. J. Comp. Neurol. 193, 467-508. doi: 10.1002/cne.901930211

Kershaw, E. E., and Flier, J. S. (2004). Adipose tissue as an endocrine organ. J. Clin. Endocrinol. Metab. 89, 2548-2556. doi: 10.1210/jc.2004-0395

King, T. L., Heesch, C. M., Clark, C. G., Kline, D. D., and Hasser, E. M. (2012). Hypoxia activates nucleus tractus solitarii neurons projecting to the paraventricular nucleus of the hypothalamus. Am. J. Physiol. Regul. Integr. Comp. Physiol. 302, R1219-R1232. doi: 10.1152/ajpregu.00028.2012

Kline, D. D. (2008). Plasticity in glutamatergic NTS neurotransmission. Respir. Physiol. Neurobiol. 164, 105-111. doi: 10.1016/j.resp.2008.04.013

Kline, D. D., Ramirez-Navarro, A., and Kunze, D. L. (2007). Adaptive depression in synaptic transmission in the nucleus of the solitary tract after in vivo chronic intermittent hypoxia: evidence for homeostatic plasticity. J. Neurosci. 27, 4663-4673. doi: 10.1523/JNEUROSCI.4946-06.2007

Koshiya, N., and Guyenet, P. G. (1994). A5 noradrenergic neurons and the carotid sympathetic chemoreflex. Am. J. Physiol. 267, R519-R526.

Koshiya, N., and Guyenet, P. G. (1996a). NTS neurons with carotid chemoreceptor inputs arborize in the rostral ventrolateral medulla. Am. J. Physiol. 270, R1273-R1278.

Koshiya, N., and Guyenet, P. G. (1996b). Tonic sympathetic chemoreflex after blockade of respiratory rhythmogenesis in the rat. J. Physiol. 491(Pt 3), 859-869.

Kubin, L., Alheid, G. F., Zuperku, E. J., and McCrimmon, D. R. (2006). Central pathways of pulmonary and lower airway vagal afferents. J. Appl. Physiol. 101, 618-627. doi: 10.1152/japplphysiol.00252.2006

Kubo, T., Hagiwara, Y., Sekiya, D., and Fukumori, R. (1998). Evidence for involvement of the lateral parabrachial nucleus in mediation of cholinergic inputs to neurons in the rostral ventrolateral medulla of the rat. Brain Res. 789, 23-31. doi: 10.1016/S0006-8993(97)01452-2

Kumada, M., Terui, N., and Kuwaki, T. (1990). Arterial baroreceptor reflex: its central and peripheral neural mechanisms. Prog. Neurobiol. 35, 331-361. doi: 10.1016/0301-0082(90)90036-G

Lahiri, S., Roy, A., Baby, S. M., Hoshi, T., Semenza, G. L., and Prabhakar, N. R. (2006). Oxygen sensing in the body. Prog. Biophys. Mol. Biol. 91, 249-286. doi 10.1016/j.pbiomolbio.2005.07.001

Lindsey, B. G., Arata, A., Morris, K. F., Hernandez, Y. M., and Shannon, R. (1998) Medullary raphe neurones and baroreceptor modulation of the respiratory motor pattern in the cat. J. Physiol. 512(Pt 3), 863-882. doi: 10.1111/j.14697793.1998.863bd.x

Loewy, A. D. (1990). "Central autonomic pathways," in Central Regulation of Autonomic Functions, eds A. D. Loewy and K. M. Spyer (New York, NY: Oxford University Press), 88-103.

Machado, B. H. (2001). Neurotransmission of the cardiovascular reflexes in the nucleus tractus solitarii of awake rats. Ann. N.Y. Acad. Sci. 940, 179-196. doi: 10.1111/j.1749-6632.2001.tb03676.x

Machado, B. H., and Bonagamba, L. G. (2005). Antagonism of glutamate receptors in the intermediate and caudal NTS of awake rats produced no changes in the hypertensive response to chemoreflex activation. Auton. Neurosci. 117, 25-32. doi: 10.1016/j.autneu.2004.10.004

Machado, B. H., Castania, J. A., Bonagamba, L. G., and Salgado, H. C. (2000). Neurotransmission of autonomic components of aortic baroreceptor afferents in the NTS of awake rats. Am. J. Physiol. Heart Circ. Physiol. 279, H67-H75.

Malli, F., Papaioannou, A. I., Gourgoulianis, K. I., and Daniil, Z. (2010). The role of leptin in the respiratory system: an overview. Respir. Res. 11:152. doi: 10.1186/1465-9921-11-152

Malpas, S. C. (1998). The rhythmicity of sympathetic nerve activity. Prog Neurobiol. 56, 65-96. doi: 10.1016/S0301-0082(98)00030-6

Mandel, D. A., and Schreihofer, A. M. (2006). Central respiratory modulation of barosensitive neurones in rat caudal ventrolateral medulla. J. Physiol. 572, 881-896. doi: 10.1113/jphysiol.2005.103622

Mandel, D. A., and Schreihofer, A. M. (2009). Modulation of the sympathetic response to acute hypoxia by the caudal ventrolateral medulla in rats. J. Physiol. 587, 461-475. doi: 10.1113/jphysiol.2008.161760

Marchenko, V., and Sapru, H. N. (2000). Different patterns of respiratory and cardiovascular responses elicited by chemical stimulation of dorsal medulla in the rat. Brain Res. 857, 99-109. doi: 10.1016/S0006-8993(99)02377-X

Mark, A. L., Agassandian, K., Morgan, D. A., Liu, X., Cassell, M. D., and Rahmouni, K. (2009). Leptin signaling in the nucleus tractus solitarii increases sympathetic nerve activity to the kidney. Hypertension 53, 375-380. doi: 10.1161/HYPERTENSIONAHA.108.124255

McAllen, R. M. (1987). Central respiratory modulation of subretrofacial bulbospinal neurones in the cat. J. Physiol. 388, 533-545.

McBryde, F. D., Abdala, A. P., Hendy, E. B., Pijacka, W., Marvar, P., Moraes, D. J., et al. (2013). The carotid body as a putative therapeutic target for the treatment of neurogenic hypertension. Nat. Commun. 4:2395. doi: 10.1038/ncomms3395

McCrimmon, D. R., Speck, D. F., and Feldman, J. L. (1987). Role of the ventrolateral region of the nucleus of the tractus solitarius in processing respiratory afferent input from vagus and superior laryngeal nerves. Exp. Brain Res. 67, 449-459. doi: 10.1007/BF00247278

Mei, L., Zhang, J., and Mifflin, S. (2003). Hypertension alters GABA receptormediated inhibition of neurons in the nucleus of the solitary tract Am. J. Physiol. Regul. Integr. Comp. Physiol. 285, R1276-R1286. doi: 10.1152/ajpregu.00255.2003.

Mifflin, S. W. (1992). Arterial chemoreceptor input to nucleus tractus solitarius. Am. J. Physiol. 263, R368-R375.

Mifflin, S. W., and Felder, R. B. (1990). Synaptic mechanisms regulating cardiovascular afferent inputs to solitary tract nucleus. Am. J. Physiol. 259, H653-H661.

Mifflin, S. W., Spyer, K. M., and Withington-Wray, D. J. (1988). Baroreceptor inputs to the nucleus tractus solitarius in the cat: modulation by the hypothalamus. J. Physiol. 399, 369-387.

Miyawaki, T., Pilowsky, P., Sun, Q. J., Minson, J., Suzuki, S., Arnolda, L., et al (1995). Central inspiration increases barosensitivity of neurons in rat rostral ventrolateral medulla. Am. J. Physiol. 268, R909-R918.

Molkov, Y. I., Bacak, B. J., Dick, T. E., and Rybak, I. A. (2013). Control of breathing by interacting pontine and pulmonary feedback loops. Front. Neural Circuits 7:16. doi: $10.3389 /$ fncir.2013.00016

Molkov, Y. I., Zoccal, D. B., Moraes, D. J., Paton, J. F., Machado, B. H., and Rybak, I. A. (2011). Intermittent hypoxia-induced sensitization of central chemoreceptors contributes to sympathetic nerve activity during late expiration in rats. J. Neurophysiol. 105, 3080-3091. doi: 10.1152/jn.00070.2011

Moraes, D. J., Bonagamba, L. G., Zoccal, D. B., and Machado, B. H. (2011) Modulation of respiratory responses to chemoreflex activation by L-glutamate and ATP in the rostral ventrolateral medulla of awake rats. Am. J. Physiol. Regul. Integr. Comp. Physiol. 300, R1476-R1486. doi: 10.1152/ajpregu.00825.2010

Moraes, D. J., Da Silva, M. P., Bonagamba, L. G., Mecawi, A. S., Zoccal, D. B., Antunes-Rodrigues, J., et al. (2013). Electrophysiological properties of rostral ventrolateral medulla presympathetic neurons modulated by the respiratory network in rats. J. Neurosci. 33, 19223-19237. doi: 10.1523/JNEUROSCI.304113.2013

Moraes, D. J., Dias, M. B., Cavalcanti-Kwiatkoski, R., Machado, B. H., and Zoccal, D. B. (2012a). Contribution of retrotrapezoid/parafacial respiratory region to the expiratory-sympathetic coupling in response to peripheral chemoreflex in rats. J. Neurophysiol. 108, 882-890. doi: 10.1152/jn.001 93.2012

Moraes, D. J., Machado, B. H., and Paton, J. F. (2014). Specific respiratory neuron types have increased excitability that drive presympathetic 
neurones in neurogenic hypertension. Hypertension 63, 1309-1318. doi: 10.1161/HYPERTENSIONAHA.113.02283

Moraes, D. J., Zoccal, D. B., and Machado, B. H. (2012b). Medullary respiratory network drives sympathetic overactivity and hypertension in rats submitted to chronic intermittent hypoxia. Hypertension 60, 1374-1380. doi: 10.1161/HYPERTENSIONAHA.111.189332

Moraes, D. J., Zoccal, D. B., and Machado, B. H. (2012c). Sympathoexcitation during chemoreflex active expiration is mediated by L-glutamate in the RVLM/Botzinger complex of rats. J. Neurophysiol. 108, 610-623. doi: 10.1152/jn.00057.2012

Narkiewicz, K., Van De Borne, P. J. H., Montano, N., Dyken, M. E., Phillips, B. G., and Somers, V. K. (1998). Contribution of tonic chemoreflex activation to sympathetic activity and blood pressure in patients with obstructive sleep apnea. Circulation 97, 943-945. doi: 10.1161/01.CIR.97.10.943

Niewinski, P., Janczak, D., Rucinski, A., Jazwiec, P., Sobotka, P. A., Engelman, Z J., et al. (2013). Carotid body removal for treatment of chronic systolic heart failure. Int. J. Cardiol. 168, 2506-2509. doi: 10.1016/j.ijcard.2013.03.011

Olivan, M. V., Bonagamba, L. G., and Machado, B. H. (2001). Involvement of the paraventricular nucleus of the hypothalamus in the pressor response to chemoreflex activation in awake rats. Brain Res. 895, 167-172. doi: 10.1016/S0006-8993(01)02067-4

Patel, S. R., Palmer, L. J., Larkin, E. K., Jenny, N. S., White, D. P., and Redline, S. (2004). Relationship between obstructive sleep apnea and diurnal leptin rhythms. Sleep 27, 235-239.

Peña, F., and Ramirez, J.-M. (2005). Hypoxia-induced changes in neuronal network properties. Mol. Neurobiol. 32, 251-283. doi: 10.1385/MN:32:3:251

Peng, Y.-J., Overholt, J. L., Kline, D., Kumar, G. K., and Prabhakar, N. R. (2003) Induction of sensory long-term facilitation in the carotid body by intermittent hypoxia: implications for recurrent apneas. Proc. Natl. Acad. Sci. U.S.A. 100, 10073-10078. doi: 10.1073/pnas.1734109100

Peters, J. H., McDougall, S. J., Kellett, D. O., Jordan, D., Llewellyn-Smith, I. J., and Andresen, M. C. (2008). Oxytocin enhances cranial visceral afferent synaptic transmission to the solitary tract nucleus. J. Neurosci. 28, 11731-11740. doi: 10.1523/JNEUROSCI.3419-08.2008

Queiroz, E. A., Okada, M. N., Fumega, U., Fontes, M. A., Moraes, M. F., and Haibara, A. S. (2011). Excitatory amino acid receptors in the dorsomedial hypothalamus are involved in the cardiovascular and behavioural chemoreflex responses. Exp. Physiol. 96, 73-84. doi: 10.1113/expphysiol.2010.054080

Rahmouni, K., Morgan, D. A., Morgan, G. M., Mark, A. L., and Haynes, W. G. (2005). Role of selective leptin resistance in diet-induced obesity hypertension. Diabetes 54, 2012-2018. doi: 10.2337/diabetes.54.7.2012

Reddy, M. K., Patel, K. P., and Schultz, H. D. (2005). Differential role of the paraventricular nucleus of the hypothalamus in modulating the sympathoexcitatory component of peripheral and central chemoreflexes. Am. J. Physiol. Regul. Integr. Comp. Physiol. 289, R789-R797. doi: 10.1152/ajpregu.00222.2005

Reeves, S. R., Gozal, E., Guo, S. Z., Sachleben, L. R. Jr., Brittian, K. R., Lipton, A. J., et al. (2003). Effect of long-term intermittent and sustained hypoxia on hypoxic ventilatory and metabolic responses in the adult rat. J. Appl. Physiol. 95, 1767-1774. doi: 10.1152/japplphysiol.00759.2002

Reis, D. J., Granata, A. R., Perrone, M. H., and Talman, W. T. (1981). Evidence that glutamic acid is the neurotransmitter of baroreceptor afferent terminating in the nucleus tractus solitarius (NTS). J. Auton. Nerv. Syst. 3, 321-334. doi: 10.1016/0165-1838(81)90073-4

Rey, S., Del Rio, R., Alcayaga, J., and Iturriaga, R. (2004). Chronic intermittent hypoxia enhances cat chemosensory and ventilatory responses to hypoxia. J. Physiol. 560, 577-586. doi: 10.1113/jphysiol.2004.072033

Richter, D. W., and Seller, H. (1975). Baroreceptor effects on medullary respiratory neurones of the cat. Brain Res. 86, 168-171. doi: 10.1016/0006-8993(75) 90651-4

Ross, C. A., Ruggiero, D. A., Park, D. H., Joh, T. H., Sved, A. F., FernandezPardal, J., et al. (1984). Tonic vasomotor control by the rostral ventrolateral medulla: effect of electrical or chemical stimulation of the area containing $\mathrm{C} 1$ adrenaline neurons on arterial pressure, heart rate, and plasma catecholamines and vasopressin. J. Neurosci. 4, 474-494.

Ruggiero, D. A., Giuliano, R., Anwar, M., Stornetta, R., and Reis, D. J. (1990). Anatomical substrates of cholinergic-autonomic regulation in the rat. J. Comp. Neurol. 292, 1-53. doi: 10.1002/cne.902920102

Sapru, H. N. (1996). Carotid chemoreflex. Neural pathways and transmitters. $A d v$. Exp. Med. Biol. 410, 357-364. doi: 10.1007/978-1-4615-5891-0_55
Sato, M. A., Colombari, E., and Morrison, S. F. (2002). Inhibition of neurons in commissural nucleus of solitary tract reduces sympathetic nerve activity in SHR. Am. J. Physiol. Heart Circ. Physiol. 282, H1679-H1684. doi: 10.1152/ajpheart.00619.2001.

Sato, M. A., Menani, J. V., Ubríaco-Lopes, O., and Colombari, E. (2001). Lesions of the commissural nucleus of the solitary tract reduce arterial pressure in spontaneously hypertensive rats. Hypertension 38, 560-564. doi: 10.1161/01.HYP.38.3.560

Schafer, H., Pauleit, D., Sudhop, T., Gouni-Berthold, I., Ewig, S., and Berthold, H. K. (2002). Body fat distribution, serum leptin, and cardiovascular risk factors in men with obstructive sleep apnea. Chest 122, 829-839. doi: 10.1378/chest.122.3.829

Schreihofer, A. M., and Guyenet, P. G. (2003). Baro-activated neurons with pulsemodulated activity in the rat caudal ventrolateral medulla express GAD67 mRNA. J. Neurophysiol. 89, 1265-1277. doi: 10.1152/jn.00737.2002

Sellden, H., Delle, M., Sjovall, H., and Ricksten, S. E. (1987). Reflex changes in sympathetic nerve activity during mechanical ventilation with PEEP in sino-aortic denervated rats. Acta Physiol. Scand. 130, 15-24. doi: 10.1111/j.17481716.1987.tb08106.x

Shan, Z., Zubcevic, J., Shi, P., Jun, J. Y., Dong, Y., Murca, T. M., et al. (2013). Chronic knockdown of the nucleus of the solitary tract AT1 receptors increases blood inflammatory-endothelial progenitor cell ratio and exacerbates hypertension in the spontaneously hypertensive rat. Hypertension 61, 1328-1333. doi: 10.1161/HYPERTENSIONAHA.111.00156

Shigetomi, E., and Kato, F. (2004). Action potential-independent release of glutamate by $\mathrm{Ca} 2+$ entry through presynaptic $\mathrm{P} 2 \mathrm{X}$ receptors elicits postsynaptic firing in the brainstem autonomic network. J. Neurosci. 24, 3125-3135. doi: 10.1523/JNEUROSCI.0090-04.2004

Shihara, M., Hori, N., Hirooka, Y., Eshima, K., Akaike, N., and Takeshita, A. (1999). Cholinergic systems in the nucleus of the solitary tract of rats. Am. J. Physiol. 276, R1141-R1148.

Simms, A. E., Paton, J. F., Pickering, A. E., and Allen, A. M. (2009). Amplified respiratory-sympathetic coupling in the spontaneously hypertensive rat: does it contribute to hypertension? J. Physiol. 587, 597-610. doi: 10.1113/jphysiol.2008.165902

Smith, J. C., Abdala, A. P., Koizumi, H., Rybak, I. A., and Paton, J. F. (2007). Spatial and functional architecture of the mammalian brain stem respiratory network: a hierarchy of three oscillatory mechanisms. J. Neurophysiol. 98, 3370-3387. doi: 10.1152/jn.00985.2007

Smith, J. C., Ellenberger, H. H., Ballanyi, K., Richter, D. W., and Feldman, J. L. (1991). Pre-Botzinger complex: a brainstem region that may generate respiratory rhythm in mammals. Science 254, 726-729. doi: 10.1126/science.1683005

Somers, V. K. (1995). Sympathetic neural mechanisms in obstructive sleep apnea. J. Clin. Investig. 96, 1897-1904. doi: 10.1172/JCI118235

Song, G., Xu, H., Wang, H., Macdonald, S. M., and Poon, C. S. (2011) Hypoxia-excited neurons in NTS send axonal projections to KollikerFuse/parabrachial complex in dorsolateral pons. Neuroscience 175, 145-153. doi: 10.1016/j.neuroscience.2010.11.065

Spary, E. J., Maqbool, A., Saha, S., and Batten, T. F. (2008). Increased GABA B receptor subtype expression in the nucleus of the solitary tract of the spontaneously hypertensive rat. J. Mol. Neurosci. 35, 211-224. doi: 10.1007/s12031-008-9055-9 Staessen, J. A., Wang, J., Bianchi, G., and Birkenhager, W. H. (2003). Essential hypertension. Lancet 361, 1629-1641. doi: 10.1016/S0140-6736(03)13302-8

Sun, Q. J., Minson, J., Llewellyn-Smith, I. J., Arnolda, L., Chalmers, J., and Pilowsky, P. (1997). Botzinger neurons project towards bulbospinal neurons in the rostral ventrolateral medulla of the rat. J. Comp. Neurol. 388, 23-31. doi: 10.1002/(SICI)1096-9861(19971110)388:1<23::AID-CNE2>3.0.CO;2-Q [pii].

Takakura, A. C., Moreira, T. S., Colombari, E., West, G. H., Stornetta, R. L., and Guyenet, P. G. (2006). Peripheral chemoreceptor inputs to retrotrapezoid nucleus (RTN) CO2-sensitive neurons in rats. J. Physiol. 572, 503-523. doi: 10.1113/jphysiol.2005.103788

Taxini, C. L., Takakura, A. C., Gargaglioni, L. H., and Moreira, T. S. (2011). Control of the central chemoreflex by A5 noradrenergic neurons in rats. Neuroscience 199, 177-186. doi: 10.1016/j.neuroscience.2011.09.068

Teppema, L. J., Veening, J. G., Kranenburg, A., Dahan, A., Berkenbosch, A., and Olievier, C. (1997). Expression of c-fos in the rat brainstem after exposure to hypoxia and to normoxic and hyperoxic hypercapnia. J. Comp. Neurol. 388, 169-190. doi: 10.1002/(SICI)1096-9861(19971117)388:2<169::AIDCNE1>3.0.CO;2-\# 
Toney, G. M., Pedrino, G. R., Fink, G. D., and Osborn, J. W. (2010). Does enhanced respiratory-sympathetic coupling contribute to peripheral neural mechanisms of angiotensin II-salt hypertension? Exp. Physiol. 95, 587-594. doi: 10.1113/expphysiol.2009.047399

Van Giersbergen, P. L., Palkovits, M., and De Jong, W. (1992). Involvement of neurotransmitters in the nucleus tractus solitarii in cardiovascular regulation. Physiol. Rev. 72, 789-824.

Waki, H., Gouraud, S. S., Maeda, M., and Paton, J. F. (2008). Specific inflammatory condition in nucleus tractus solitarii of the SHR: novel insight for neurogenic hypertension? Auton. Neurosci. 142, 25-31. doi: 10.1016/j.autneu.2008.07.003

Yu, J., Roberts, A. M., and Joshua, I. G. (1990). Lung inflation evokes reflex dilation of microvessels in rat skeletal muscle. Am. J. Physiol. 258, H939-H945.

Zhang, W., Carreno, F. R., Cunningham, J. T., and Mifflin, S. W. (2008). Chronic sustained and intermittent hypoxia reduce function of ATP-sensitive potassium channels in nucleus of the solitary tract. Am. J. Physiol. Regul. Integr. Comp. Physiol. 295, R1555-R1562. doi: 10.1152/ajpregu.90390.2008

Zhang, W., and Mifflin, S. (2010). Chronic hypertension enhances presynaptic inhibition by baclofen in the nucleus of the solitary tract. Hypertension 55, 481-486. doi: 10.1161/HYPERTENSIONAHA.109.145151

Zhang, W., and Mifflin, S. W. (1993). Excitatory amino acid receptors within NTS mediate arterial chemoreceptor reflexes in rats. Am. J. Physiol. 265, H770-H773.

Zhou, S. Y., and Gilbey, M. P. (1992). Respiratory-related activity of lower thoracic and upper lumbar sympathetic preganglionic neurones in the rat. J. Physiol. 451, 631-642.

Zhou, Z., Champagnat, J., and Poon, C. S. (1997). Phasic and long-term depression in brainstem nucleus tractus solitarius neurons: differing roles of AMPA receptor desensitization. J. Neurosci. 17, 5349-5356.

Zoccal, D. B., Bonagamba, L. G., Oliveira, F. R., Antunes-Rodrigues, J., and Machado, B. H. (2007). Increased sympathetic activity in rats submitted to chronic intermittent hypoxia. Exp. Physiol. 92, 79-85. doi: 10.1113/expphysiol.2006.035501

Zoccal, D. B., Bonagamba, L. G., Paton, J. F., and Machado, B. H. (2009). Sympathetic-mediated hypertension of awake juvenile rats submitted to chronic intermittent hypoxia is not linked to baroreflex dysfunction. Exp. Physiol. 94, 972-983. doi: 10.1113/expphysiol.2009.048306

Zoccal, D. B., Simms, A. E., Bonagamba, L. G., Braga, V. A., Pickering, A. E., Paton, J. F., et al. (2008). Increased sympathetic outflow in juvenile rats submitted to chronic intermittent hypoxia correlates with enhanced expiratory activity. J. Physiol. 586, 3253-3265. doi: 10.1113/jphysiol.2008. 154187

Conflict of Interest Statement: The authors declare that the research was conducted in the absence of any commercial or financial relationships that could be construed as a potential conflict of interest.

Received: 22 April 2014; paper pending published: 12 May 2014; accepted: 09 June 2014; published online: 25 June 2014.

Citation: Zoccal DB, Furuya WI, Bassi M, Colombari DSA and Colombari E (2014) The nucleus of the solitary tract and the coordination of respiratory and sympathetic activities. Front. Physiol. 5:238. doi: 10.3389/fphys.2014.00238

This article was submitted to Integrative Physiology, a section of the journal Frontiers in Physiology.

Copyright (c) 2014 Zoccal, Furuya, Bassi, Colombari and Colombari. This is an openaccess article distributed under the terms of the Creative Commons Attribution License (CC BY). The use, distribution or reproduction in other forums is permitted, provided the original author(s) or licensor are credited and that the original publication in this journal is cited, in accordance with accepted academic practice. No use, distribution or reproduction is permitted which does not comply with these terms. 